\title{
The Associations Between Artistic Creativity and Resilience Among High School Female Students in Beijing
}

\author{
Wanrong Xue
}

\author{
Beijing Royal School \\ *Corresponding author. Email: xuewanrong0507@163.com
}

\begin{abstract}
Mental illness is a controversial health killer in recent years, especially in China. According to the data disclosed by the World Health Organization (WHO), more than 350million patients were diagnosed with depression worldwide in 2007. Significantly, China has the highest number of people diagnosed with depression, which has reached 30million. Among them, 24\% of teenagers were depressed, with 7.4 percent suffering from major depression. (Fu, et al. 2021) The considerable amount of adolescent patients reflects the weakness of mental health counseling in high school education. At the same time, it is easy to observe that artists have a high rate of mental illness and even suicide. This paper researched the correlation between creativity and resilience among female high school students in Beijing through statistic. The results of the statistic show that art students showed significantly weaker resilience than regular students. The creativity of students was negatively correlated with their resilience. The ultimate purpose of this paper is to help improve the mental health education of high school students. Also, the phenomenon of artists suffering from mental illness or even committing suicide should be reduced or even eliminated in new era.
\end{abstract}

Keywords: Artistic Creativity, Resilience, High School Female Students

\section{INTRODUCTION}

Most high-achieving artists are known as maniacs and eccentrics, suffering from melancholic states such as mood disorders. Dutch post-impressionist van Gogh suffered from severe depression and repeatedly attempted suicide [5]. Famous fairy tale writer Hans Christian Andersen suffered from severe depression and often felt anxious. Zhang Guorong, a Hong Kong actor suffering from depression, finally committed suicide by jumping from the 24th floor of a hotel. Swedish musician Tim committed suicide after years of depression (Billboard, 2018). According to the above examples, many artists suffer from depression, which even leads to the death of many artists. These examples illustrate how mental illness affects creative people.

According to the data disclosed by the World Health Organization (WHO), more than 350 million patients were diagnosed with depression worldwide in 2007, with the increase rate of about $18 \%$ in the past decade. Among all the countries, China has the highest number of people diagnosed with depression, which has reached 30 million.
In 2007 , the number of people suffering from depression in China reached 30 million, making up $6.1 \%$ of the total Chinese population. Depression has become a worldwide concern and one of the killers of human health.

Especially in China, the rates and numbers of people suffering from depression are alarming. By calculation, China accounts for 8.57 percent of the world's patents. Teenagers make up the majority of the depressed population. According to the inter-annual Evolution of Adolescent Mental Health from 2009 to 2020, Twentyfour percent of teens were depressed, with 7.4 percent suffering from major depression. The proportion of mild depression was $17.2 \%, 0.4 \%$ higher than in 2009 [6]. According to their report, between 2009and 2020, the mental health status of adolescents decreased. While the sample of teens with major depression remained roughly the same, the total number of teens with depression increased. Also in the this report, another statistic worth noting is that girls are more depressed than boys. The prevalence of depression was 18.9 percent for girls, 3.2 percent higher than 15.8 percent for boys. As a result, the research of depression in female high school students is valuable for the mental health of teenagers. This paper 
researched the relationship between creativity and resilience of Beijing high school female students through an observational study The present study was conducted to compare the resilience between art students and nonart students.

\section{WHAT IS RESILIENCE}

Resilience is the capacity to maintain stable levels of functioning, as well as positive emotions and generative experiences, following or under conditions of significant adversity (Mancini, 2011). It is a positive characteristic that helps people adapt to a negative environment. The level of resilience often determines a person's attitude towards problems and further affects their behaviors when facing challenges. People with higher resilience are more able to cope with difficulties and control their emotions. As such high resilience protects people's mental health (Mancini, 2011).

With the birth of resilience and the deepening of its research and understanding, people's views on the psychological development of individuals in adversity under the traditional concept have been shaken, and their cognition on the impact of the environment has also been enriched. Researchers think that resilience is closely related to mental health, because it not only can predict stress after the individual's psychological health level, is an important indicator of mental health [2]

According to Jing et al. 's research, resilience is positively correlated with positive emotions and general well-being, and negatively correlated with anxiety and depression. Positive emotions are negatively correlated with anxiety and depression, and positively correlated with overall well-being [4]. In conclusion, people with low resilience are likely to experience negative emotions and anxiety when facing difficulties, therefore have more trouble dealing with setbacks and failures. On the contrary, high resilient individuals are more able to deal with problems in a positive emotion and keep calm than less resilient people. Also, people with high resilience are happier in life than people with low resilience. Because of the associate between resilience and anxiety when facing difficult, resilience is significant in dealing with setbacks.

The importance of resilience has long been proven. People who lack resilience can also improve it through training and education. For example, the Outwarard Bound Training, also known as OB Training, is a kind of basic principles of cognitive psychology, emotional psychology, behavioral psychology, psychological counseling, treatment and health, through the creation of situations for individuals to participate in, while completing the "task" to cultivate the good psychological quality of the trainees. Psychological training methods to improve mental health level. OB training can significantly improve the mental resilience of middle school students [7].

\subsection{Artistic Creativity and Resilience}

Before studying the correlation between creativity and resilience, it is important to understand the definition of creativity. Creativity is a phenomenon whereby something new, original and somehow valuable is formed. Psychologists have long wrestled with the definition of creativity. In the early days, psychologists tended to study the personality traits revealed by creativity, using specific traits to tell whether someone was creative or not. But the definition is hard to pin down. As a result, psychologists often define creativity differently. Creativity refers to the most specific abilities of creative people (Guilford, 1950, p. 444). J. P. Guilford's definition of creativity is rather vague, not referring to any specific personality trait, but merely to the most specific abilities. But his views have earned considerable recognition and acclaim throughout history. However, the characteristics of creative people are universal.

Creative people can always create value for society, every creation is a part of human history. There is a need for creative people in professions and professions such as music, art and science. Creativity is often associated with curiosity, observation, and imagination, and creative people are associated with more traits.

There are some existing conclusions and research on the relationship between resilience and creativity. According to Wang's research, psychological resilience has a significant positive impact on resilience. Psychological security completely mediated the effect of resilience on creativity [8]. In conclusion, resilience can regulate creativity through psychological security. Whether creativity can affect resilience is an extended question. This is also the inspiration of this article. This paper examined the correlation between resilience and creativity among high school female students in Beijing through statistical survey and data analysis. The results of the research have implications for the mental health of teenagers. More resilience knowledge could also make schools more experienced in protecting students' mental health. In the present study, we aim to explore the following two questions including

1. Do art majors have less resilience than science majors?

2. Is there an association between creativity and resilience?

\section{METHOD}

\subsection{Participants}

The research used sample random sampling to select the participants. The experiment was a single-blind 
experiment. I sent two questionnaires to the headteacher of an art class and a headteacher of an ordinary class and asked them to help me randomly find 25 students to fill in the questionnaires. These two teachers did not know the content and purpose of this experiment, which reduced the teachers' bias caused by subjective factors. Since the teachers of ordinary classes only collected 14samples, 6 of the samples were obtained through paid questionnaires.

The participants consisted of 50 Chinese female high school students from Beijing. Remove 2 invalid samples, the sample size was 48.28 of the participants are students major in art. Another 20 of them are students from other majors. Art students were used to representing creative individuals. Average students were used to representing the non-creative individuals. Art students are those who will take art majors in the national college entrance examinations. Such as music, dance, drama, painting, acting and other arts. If a student wants to become an art student, he/she must take a unified test of art before. The test scores will be the main basis for colleges and universities to admit art students. Some schools require students to be members of a local school's art troupe or to have won a national or municipal competition. Some schools only require students to meet the requirements of the year. Art students take one more art test than non-art students. Usually they are under more pressure than the non-art student. And the art exams are very competitive. They spend most of their free time studying art. It also makes it difficult for them to communicate with non-art classmates.

As a result of China's college entrance examination policy, students majoring in the art are often condemned and discriminated against by public opinion for not taking the college entrance examination. This has a negative impact on the mental health of high school art students. Coupling with the pressure of college entrance examinations, those factors affect the physical and mental health of many high school art students.

According to the American Psychological Association's ethical guidelines, participation in this research was voluntary. All of the participants were informed of potential risks that they might be analyzed individually as outliers. The results of the research were only used for scientific study. Participants' right to privacy was protected and the personal information of participants was kept confidential. Every participant can withdraw unconditionally for free.

\subsection{Measures: the Conner-Davidson Resilience Scale}

Connor Davidson Resilience Scale (CD-RISC) was selected to measure resilience. The Chinese version revised by Xiao Nan of The Chinese University of Hong Kong (2007) was applied. It is a self-report questionnaire consisting of 25 items, including 3 dimensions: tenacity, self-reliance, and optimism. The reliability of the whole scale and the three subscales was good, and the Cronbach alpha coefficient was $0.91,0.88,0.88$ and 0.60 , respectively. The questions were rated on a 5-point Likert scale from 1(never) to 5(almost always). Participants were required to rate how closely the statement apply them. A sample question is "I can adapt to change". The total score of the scale is the average score of all 25 questions, while the score of the subscale is the average score of the corresponding questions of each subscale.

On average, art students $(\mathrm{M}=54.96 \mathrm{SE}=2.96)$ show significantly weaker resilience than regular students $(\mathrm{M}$ $=64.55, \mathrm{SE}=3.45), t(46)=-2.10, p<.05$.

\section{DISCUSSION}

According to this research, art students have significantly lower resilience than non-art students. Some art students lack communication with others. Studying art makes art students to use most of their free time to practice artistic skills. Art students don't have enough time to socialize. Most schools in Beijing finish school between five and six o'clock in the afternoon. China ranks first among countries in terms of workload, reaching 13.8 hours per week. This makes opportunities for art students to communicate with their peers very rare. To devote all the time they had to art, many art students rarely have the chance to hang out with friends. It makes them feel lonely. And studies have shown that communication ability was negatively correlated with loneliness, positively correlated with having meaning and seeking meaning, while loneliness was negatively correlated with both of them. The mediating effect of loneliness between communicative competence and meaningful life is regulated by grade [1].

As a result of learning art major in the early years, their hobbies are quite different from those of non-art students. Most students like fashionable new things rather than traditional art. In 2016, a survey on the interests of Chinese high school students revealed that $40.9 \%$ of the students chose "Internet access", 30.1\% of the students chose "Watching TV and listening to the radio", and only $14 \%$ chose "Reading extracurricular books", and the students" physical exercise" time was also less than 7.5\%. Seventy-one percent of Chinese students spend a lot of time outside of class surfing on the Internet, watching TV, and listening to the radio [10].

According to the survey results, it can be found that high school students spend most of their extracurricular time watching TV and listening to the radio, and artrelated hobbies account for a few of the proportion. Art students are more willing to communicate with other art students who share similar interests than with non-art students. However, only a few students choose to study art in comprehensive high school, making art-students a 
minority group who have few chances to make friends with people with similar interests with them.

According to the survey results of the relationship between college students' interpersonal ability and psychological resilience: Interpersonal ability has a significant positive correlation with psychological resilience, which shows that the higher the interpersonal communication score, the greater the psychological resilience score is [9]. As such, art students who lack interpersonal skills and social support are vulnerable and show weak resilience.

\section{CONCLUSION}

In terms of sample size, the amount of number of valuable samples in the research was less than 50. 50was exactly a small sample, so the results of the research may not be generalized to a greater population. The sample size should be expanded to carry out a more comprehensive investigation. Also, the sample for this survey was taken from only two schools. It is not representative of all high schools in Beijing. In the future, sample extraction should be carried out in most high schools to get more accurate answers. More samples of the research can cover different types of female students in Beijing, so the results will become more reliable.

Meanwhile, the simple random sampling in this research was not standard enough. The sample was limited to two Beijing high schools. And because one of the teachers did not collect enough samples, six samples were obtained through paid questionnaires. Since the paid questionnaire was posted in a group chat with my friends, this resulted in biased samples. Art students represented the sample of creativity in this research. Through the inquiry during the research, there are also many special groups among art students. For example, students who choose art because they cannot pass other regular exams, students who are forced by their parents to study a certain subject, etc. These students may not accurately represent creativity individuals. Future studies should rule out these types of art students from the sample.

In the future, questions about the reasons for becoming an art student can be added at the end of the scale to screen valid answers. In the process of disposing of the data of the questionnaire, only female students who are actively willing to study art should be selected as valuable samples. This topic also has academic malleability and exploration space. In the future, research can include male high school students, which will effective help support the mental health of creative high school students in Beijing.

At the stages of 'Hurricanes and raging waves, people will experience bad emotions such as irritability, and repetitive changes. If they are not properly guided, high school students may op into psychological problems such as depression and bipolar depression [3]. Therefore, the mental health education of high school students is significant of the operation of China's education. Teachers need to provide psychological counseling based on factors that affect the mental health of high school students. Recruiting both male and female high school students can help us to draw a more comprehensive understanding about the correlation between resilience and creativity of Beijing high school students. Findings from this research can help parents and teachers better understand art students' mental health issues and improve their mental health.

\section{REFERENCES}

[1] Rongwei Zhang, Shaojing Ke, Rong Lian, Dan Li (2020) Relationship between interpersonal skills and life meaning: Loneliness and the role of grade. Psychology; Educational theory and educational management. B844.2

[2] Chen Jing. (2018). Research progress on the influence of mental resilience on the mental health status of secondary vocational students. Journal of Hunan University of Science and Technology (Natural Science Edition), 031(001), 82-86. Amabile, T. M.

[3] Liu Liping. (2021). Talks about mental health education in the work of high school headteachers. Basic education. G441.1983. The social psychology of creativity: A componential Conceptualization, Journal of Personality and Social Psychology, 45(2), 357-376.

[4] Zhao, J., Luo, Z., \& Wang, X. (2010). Psychological resilience, Positive emotions, and mental health of college Graduates. Chinese Journal of Health Psychology, 18(009), 1078-1080.

[5] Rosalie Arteaga et al. (E.D.)(1974). Encyclopedia Britannic.Chicago: Britannica, Inc. Anthony Mancini (2011). Resilience.

[6] Fu Xiaolan et al. (E.D.) (2021) Chinese National Mental Health Development Report. Beijing: Social Sciences Academic Press.

[7] Li Jiayu, Sun Yuangang (2020) Practical exploration of $\mathrm{OB}$ training to improve mental resilience of middle school students. OB training; Mental resilience; Middle school students. G44 1671-2684 (2020) 15-0019-03

[8] Wang Yongyue, ZHANG Ling. Psychological resilience and employee creativity: The role of psychological security and creative self-efficacy [J]. Psychological Science,2018(1):118-124.]

[9] Wen Rui-ling. The Relationship between Interpersonal competence and subjective well-being 
in College Students: The Mediating role of resilience. (Dissertation, Southwest University).

[10] Chen yufu, Weng Xianhai (2016) A survey report on high school students' reading interest. High school students, Reading interests, Surveys, Interventions.

[11] Li Yinwei(2019) On the important impact of interpersonal communication on college students. Higher Education.G645.5

[12] Li YIng(2018) The relationship between psychological resilience and interpersonal communication among college students. Resilience, Interpersonal communication, college students.

[13] Zejun Zhu(2015) discussed the importance of mental resilience to the education of senior three students. Resilience, high school senior, positive psychology. B844.2 